\title{
Dijon, abbaye Saint-Bénigne
}

Christian Sapin et Carolyn Marino Malone

\section{(2) OpenEdition \\ Journals}

\section{Édition électronique}

URL : https://journals.openedition.org/cem/866

DOI : 10.4000/cem.866

ISSN : 1954-3093

Éditeur

Centre d'études médiévales Saint-Germain d'Auxerre

\section{Édition imprimée}

Date de publication : 15 août 2004

ISSN : 1623-5770

\section{Référence électronique}

Christian Sapin et Carolyn Marino Malone, «Dijon, abbaye Saint-Bénigne », Bulletin du centre d'études médiévales d'Auxerre / BUCEMA [En ligne], 8| 2004, mis en ligne le 09 avril 2009, consulté le 22 septembre 2022. URL : http://journals.openedition.org/cem/866 ; DOI : https://doi.org/10.4000/cem. 866

Ce document a été généré automatiquement le 22 septembre 2022.

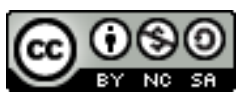

Creative Commons - Attribution - Pas d'Utilisation Commerciale - Partage dans les Mêmes Conditions 4.0 International - CC BY-NC-SA 4.0

https://creativecommons.org/licenses/by-nc-sa/4.0/ 


\title{
Dijon, abbaye Saint-Bénigne
}

\author{
Christian Sapin et Carolyn Marino Malone
}

1 Une intervention de courte durée, en août 2003, avait pour objet de déterminer par sondages diagnostics l'authenticité des structures romanes ou préromanes dans deux secteurs de la crypte de Saint-Bénigne de Dijon, construite par Guillaume de Volpiano entre 1001 et 1018. En effet, si les sources d'archives et un examen rapide des maçonneries peuvent convaincre aisément de l'importance des reconstructions du site entre 1850 et 1890, un examen plus archéologique par secteur reste indispensable pour déterminer l'authenticité de chaque partie des maçonneries.

2 À l'ouest de la rotonde, aux abords du tombeau de saint Bénigne dont subsiste le fond de la cuve du sarcophage, nous avons pu retrouver, après l'enlèvement du gravier recouvrant depuis quelques décennies l'espace du caveau, un dallage moderne dont certaines parties semblent correspondre à des réfections des années 1920. Après l'enlèvement de celui-ci en trois endroits limités, nous avons reconnu immédiatement à l'ouest le sol géologique naturel, au nord-est les vestiges d'un mortier de pose antérieur et, au sud-est, dans l'ouverture de la petite abside en hémicycle, un petit niveau d'occupation précédant le sol géologique. Les traces d'un creusement initial dans ce sol correspondant probablement au placement primitif du sarcophage. Les structures maçonnées du caveau reposent directement, sans intermédiaire, sur ce niveau naturel comme on le constate en d'autres endroits de la crypte du XI ${ }^{e}$ siècle. En attendant les analyses de mortiers, il semble bien que l'aménagement du caveau soit contemporain de la crypte. Dans le pourtour intérieur de l'abside, le nettoyage des enduits et un enlèvement limité ont permis de retrouver une fenestella originelle, bouchée semble-t-il lors de la reprise de l'abside gothique avec l'aménagement, sans doute à cette date, d'un petit escalier qui était connu par les sources et dont nous avons retrouvé un début de marche.

3 À l'est de la rotonde, dans la chapelle Saint-Jean-Baptiste, d'autres recherches d'authenticité ont montré que le sol actuel datant de la fin du XIXe siècle reposait sur le même substrat de gravier géologique. Cependant, celui-ci remonte sur plus de trente centimètres dans les piédroits du passage vers la chapelle orientale. À ce niveau, on peut reconnaître plusieurs effets de reprises avec des différences de mortier. De même, 
nous avons pu retrouver quatre états d'enduits dans deux micro sondages diagnostics, et plus à l'est des joints rubanés absents des autres maçonneries du site. Sans pouvoir encore attribuer des datations à la chronologie relative de cette zone, on peut admettre que certains éléments pourraient appartenir à des structures antérieures au $\mathrm{XI}^{\mathrm{e}}$ siècle. Seule une opération globale de recherche dans ces deux zones pourra permettre de conclure sur la chronologie et la disposition du site ; elle devrait précéder une restauration souhaitable de ces ensembles aujourd'hui très dégradés, en particulier du fait de la présence abondante du ciment des restaurations de la fin du XIX ${ }^{e}$ siècle.

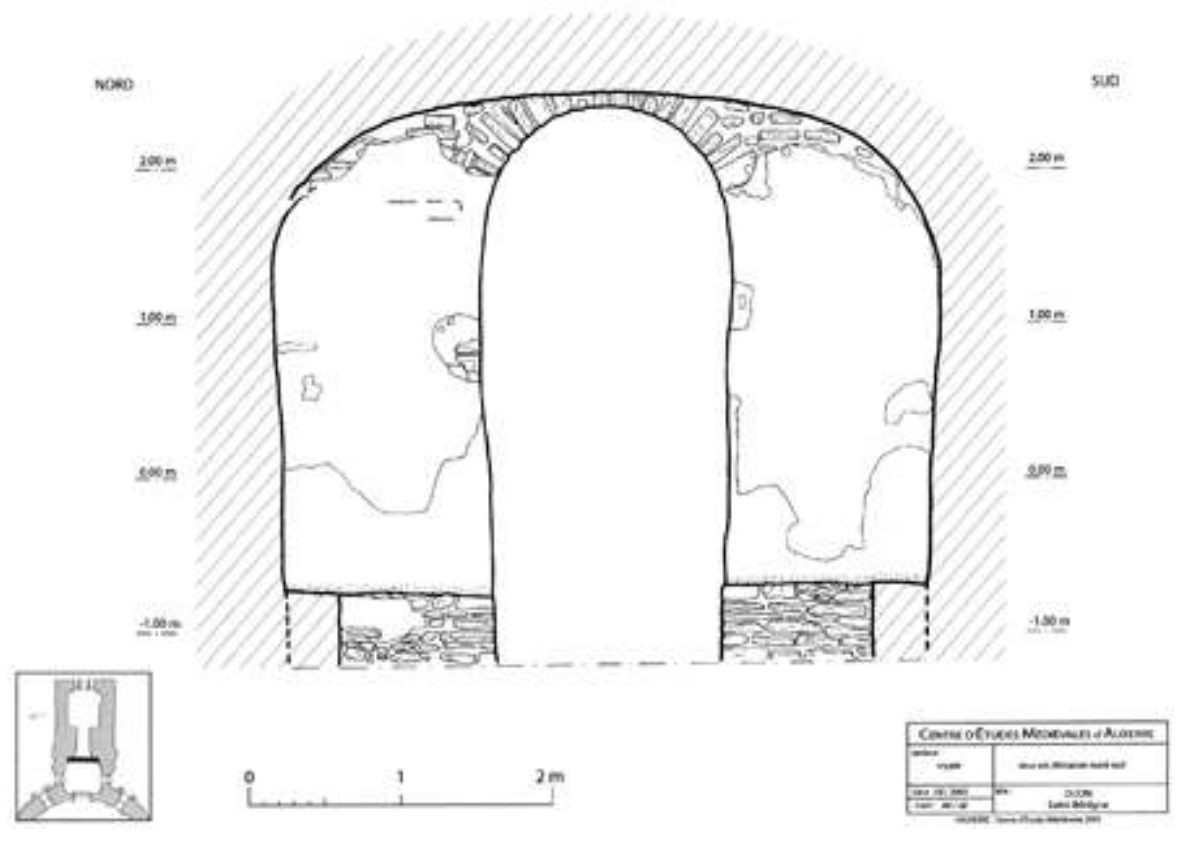

INDEX

Mots-clés : abbaye, Bénigne (saint), Saint-Bénigne de Dijon

Index géographique : France/Dijon 